\title{
Technological aspects of the production of functionalized hydrocarbon
}

oligomers

Kichurs D.B.

Department of Organic Products Technology, Lviv National Polytechnic University, UKRAINE, Lviv, Street St. Banderu, 12, 79013, E-mail: dariia.b.kichura@lpnu.ua

The paper is devoted to the oligomerization process of unsaturated hydrocarbons fractions are contained in hydrocarbon fractions of liquid products of pyrolysis in the presence of the peroxides initiator with high integral procedural decomposition temperature. Hudrocarbon fraction contains valuable unsaturated compounds, which have high reactivity and are easily subjected to oligomerization. The proposed technological schemes are based on the developed block schemes for the production of functionalized hydrocarbon oligomers on the basis of existing technologies.

Keywords: oligomerization, hydrocarbon fraction, initiator, monomer, oligomer.

\section{Introduction}

Hydrocarbon oligomers were catalyzed by oligomerization, they were effectively used as plasticizing impurities for natural and synthetic rubbers due to the high content of unsaturated bonds. Therefore, the shortage of polymeric materials with carboxyl groups, we open up many opportunities for their synthesis on the basis of cheap petrochemical raw materials. Major petroleum refineries and petrochemical enterprises have multi-tonnage waste of processes for the secondary processing of oil and its fractions, the so-called liquid pyrolysis products (RPP). Using oligomerization of such fractions, there are low molecular weight hydrocarbon oligomers known as hydrocarbon or petroleum polymer resins. RPP fractions contain more than half of unsaturated hydrocarbons, in particular, the fraction $\mathrm{C}_{5}, \mathrm{C}_{5-9}, \mathrm{C}_{9}$ contains valuable diene monomers, such as: isoprene $20 \ldots 25$, cyclopentadiene $20 \ldots 25$, piperene $10 \ldots 15$ and unsaturated aromatic and cyclic hydrocarbons, such as: 20 styrene, 15 vinyltoluenes, 10 indene, 10 dicyclopentadiene by $\%$ weight. Their number depends on the nature of the raw material: gaseous or liquid hydrocarbons, and the conditions of the process, and therefore varies in a fairly wide range of 45 ... $75 \%$ by weight $[1,2]$.

The process of modification of hudrocarbon olygomers (HOs) can be carried out both on a periodic basis (with low volumes in per unit) and on a continuous (at multi-tonnage in-vah) scheme. The replacement of the periodic process by continuous intensifies it, promotes productivity, improves the quality of products and working conditions. Periodic processes are characterized by the fact that the raw material is loaded into the apparatus for a certain time, there is a series of stages of processing in it, and then the product is unloaded. These processes have a number of disadvantages: a change in the time parameters of the technological regime, which impairs the quality of the product; low productivity; the duration of the whole process is greater than continuous; energy costs higher due to heat losses during loading and unloading periods; periodic processes are difficult to mechanize and automate. But they also have advantages: they are characterized by great flexibility, the reactor of periodic action involves less investment than a reactor operating in continuous mode.

In continuous processes, the supply of raw materials and unloading of products is carried out continuously. In these processes there are no disadvantages characteristic of periodic processes. The continuous process differs in the stability of the parameters of the technological regime (temperature, pressure, concentration of substances, etc.), which, as a rule, improves the quality of products and allows to automate the process. In order to obtain modified HOs, it is proposed to use existing equipment of the periodic production process of petroleum resins by

$2^{\text {nd }}$ INTERNATIONAL SCIENTIFIC CONFERENCE “CHEMICAL TECHNOLOGY AND ENGINEERING - 2”, JUNE 24-28 ${ }^{\text {TH }}, 2019$, LVIV, UKRAINE 
initiated oligomerization at JSC ORIANA (Kalush, Ivano-Frankivsk oblast) with additional equipment with its node for chemical modification of the finished HOs. The block scheme of the process of chemical modification of the finished HOs is shown in Fig. 1.

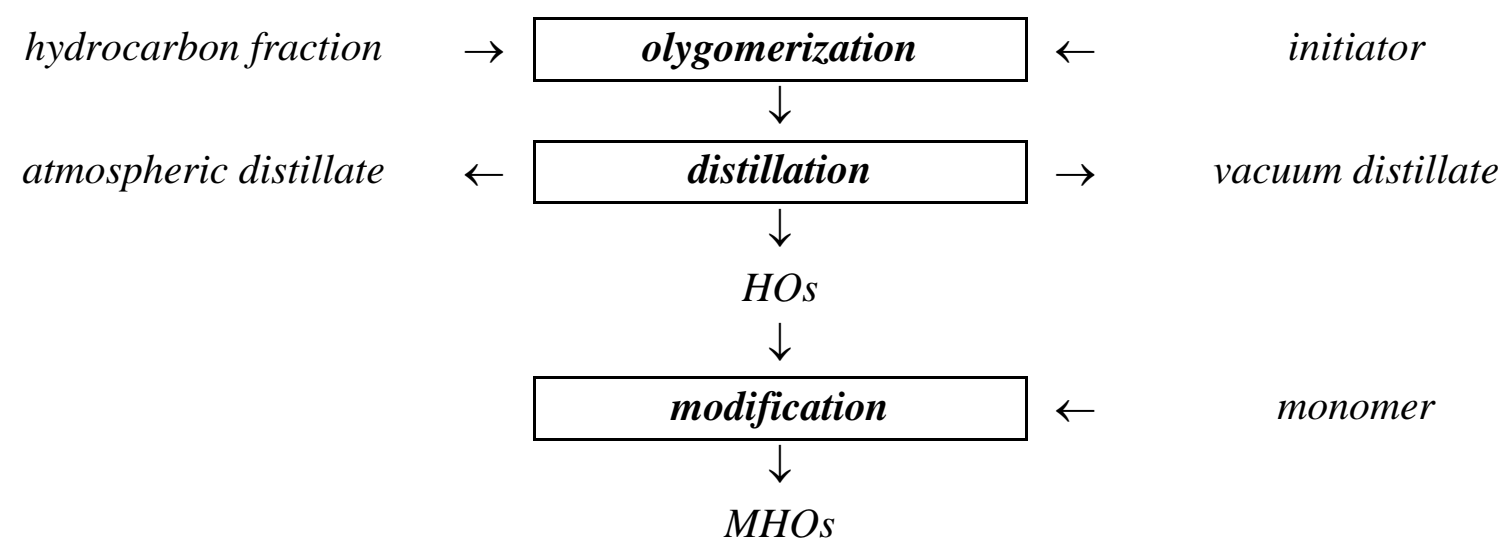

Fig. 1. Block scheme of chemical modification of hydrocarbon oligomers

Regarding the periodic process of co-oligomerization, it allows somewhat simplifying the technology of obtaining HOs with functional groups, reducing the number of stages of the process and thereby reducing the amount of process equipment. The modifier in this case is introduced directly into the reactor-polymerizer to the fraction and the initiator. Synthesis of functionalized HOs with oligomerisation of the hydrocarbon fraction $\mathrm{C}_{9} \mathrm{RPP}$ with a comonomer allows it to be obtained by continuous process. An analogue of the continuous production of HOs by the thermal oligomerization of the unsaturated RPP fractions exists at JSC LINOS (Lysychansk, Lugansk oblast). In the technological scheme it is additionally necessary to provide comonomer and initiator supply lines, as shown in Fig. 2.

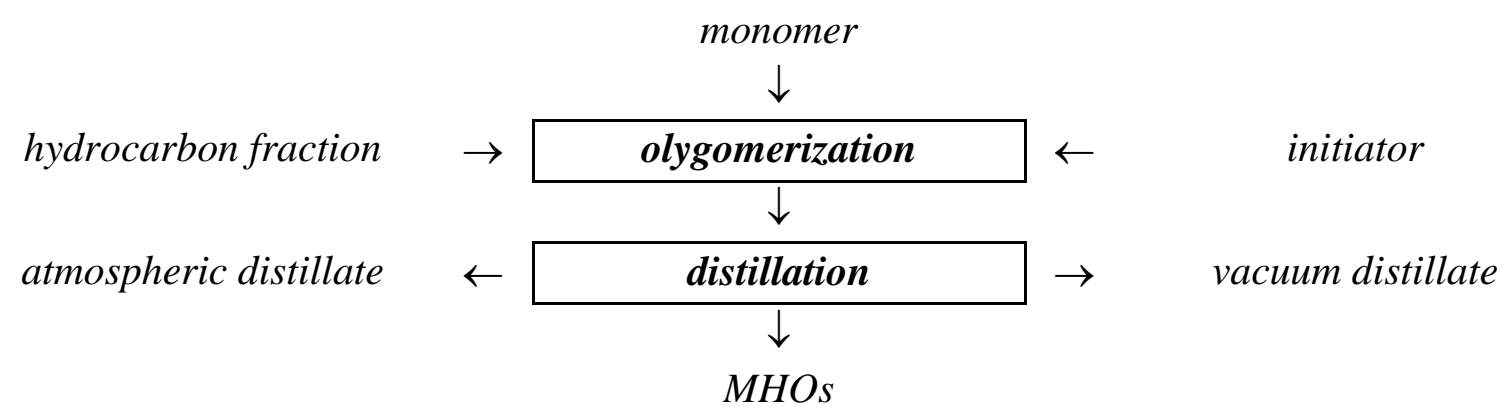

Fig. 2. Block scheme of olygomerization of hydrocarbon oligomers

\section{Conclusion}

As a result of experimental researches, functionalized hydrocarbon oligomers were obtained and the technology of their production on the industrial scale was proposed. The main technological aspects, which do not require significant investments and can be implemented without significant efforts, are worked out. By-products of production namely distillates, are also used as solvents in the paint and varnish industry, as well as components of boiler fuel.

\section{References}

[1] Dymskiy U. V., No B. I, Butov G. M. Ximia i technologia neftepolymernux smol. M.: Ximia, 1999. - $302 \mathrm{p}$.

[2] Bekirova L. Neftepolymernue smolu в SNG // Lakokrasochnie materialu. - 2008. - № 3. - P. $88-95$. 